\title{
Norm-Based Governance for Severe Collective Action Problems: Lessons from Climate Change and COVID-19
}

\author{
Leigh Raymond, Daniel Kelly and Erin P. Hennes
}

\begin{abstract}
The world has surpassed three million deaths from COVID-19, and faces potentially catastrophic tipping points in the global climate system. Despite the urgency, governments have struggled to address either problem. In this paper, we argue that COVID19 and anthropogenic climate change (ACC) are critical examples of an emerging type of governance challenge: severe collective action problems that require significant individual behavior change under conditions of hyper-partisanship and scientific misinformation. Building on foundational political science work demonstrating the potential for norms (or informal rules of behavior) to solve collective action problems, we analyze more recent work on norms from neighboring disciplines to offer novel recommendations for more difficult challenges like COVID-19 and ACC. Key insights include more attention to 1) norm-based messaging strategies that appeal to individuals across the ideological spectrum or that reframe collective action as consistent with resistant subgroups' pre-existing values, 2) messages that emphasize both the prevalence and the social desirability of individual behaviors required to address these challenges, 3) careful use of public policies and incentives that make individual behavior change easier without threatening norm internalization, and 4) greater attention to epistemic norms governing trust in different information sources. We conclude by pointing out that COVID-19 and climate change are likely harbingers of other polarized collective action problems that governments will face in the future. By connecting work on norms and political governance with a broader, interdisciplinary literature on norm psychology, motivation, and behavior change, we aim to improve the ability of political scientists and policymakers to respond to these and future collective action challenges.
\end{abstract}

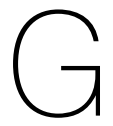

overnments have struggled to respond effectively to the global COVID-19 crisis. One year after the

100 million cases and more than three million deaths. The struggle for an effective governance response to COVID-19 outbreak began, the world had already passed evokes parallel struggles to address anthropogenic climate

Leigh Raymond (1) is Professor of Political Science at Purdue University (Iraymond@purdue.edu). His research focuses on environmental policy design, enactment, and implementation, especially the role of norms of justice and fairness in policy and behavior change. He is the author of more than thirty refereed articles or book chapters and three books, including most recently Reclaiming the Atmospheric Commons (MIT Press, 2016).

Daniel Kelly (1) is Professor of Philosophy at Purdue University (drkelly@purdue.edu). His research focuses on issues at the intersection of philosophy of mind and cognitive science, moral theory, and evolution. He is the author of a book on the genetic and cultural evolution of disgust, Yuck! The Nature and Moral Significance of Disgust (MIT Press, 2011), and has published on moral judgment and moral progress, norm psychology, norm-based social change, racial cognition, implicit bias and responsibility, and cross-cultural diversity, as well as on David Foster Wallace and free will.

Erin P. Hennes is Assistant Professor of Psychological Sciences and Political Science at Purdue University (ehennes@purdue.edu). She studies the implications of attitudes surrounding social stability and social change for basic cognition. Her research has been funded by the National Science Foundation and the National Institutes of Health.

The authors are grateful for support for this work from a Protect Purdue Innovations research grant, as well as help from Research Assistant Aijia Gao, comments by Michael Brownstein, Taylor Davis, Alex Madva, and Joshua May, and to Young Ju Ryu, Jasna Hardin, and Madhulika Shastry for help assembling the reference section 
change (ACC), another global challenge threatening human society. Solutions to both collective action problems require, in part, far-reaching and significant individual behavioral changes. Yet current governance strategies, including mandates with penalties, economic incentives, and certain types of public education campaigns, have largely failed to obtain the required behavior change among citizens in multiple nations.

Prior political science research has shown how norms of reciprocity can be instrumental for solving collective action dilemmas (Axelrod 1984, 1986; Ostrom 1998). However, in this paper we argue that COVID-19 and ACC are part of an emerging class of collective action problems marked by features that go beyond the literature's original insights. Specifically, each problem involves a high degree of complexity in a context exacerbated by misinformation and hyper-politicization. Norm-based governance approaches to collective action problems with these more challenging qualities will require more sophistication. To provide that sophistication, we draw on recent research on norm-based psychology, motivation, and behavior change to craft a novel set of norm-based governance strategies that have the potential to better influence individual behavior for COVID-19 and ACC, as well as future collective action problems that share similar qualities.

\section{Political Science Research on Norms and Collective Action Problems}

In a collective action dilemma, individuals would be better off by cooperatively adhering to a behavior that contributes to the solution of a group problem. Each person faces a "Prisoner's Dilemma," however: a temptation exists to "free ride" by letting others make sacrifices to solve the problem while acting selfishly to advance their self-interest. Political scientists have sought to understand collective action problems for decades. Olson (1965) concluded that these dilemmas are largely unsolvable, except for limited cases in which powerful groups have enough at stake to be willing to bear the full costs of addressing the problem. Grounded in the behaviorist perspective on political action, Olson's model informed a wide range of subsequent discussions of how governments can or cannot solve collective action problems, many reaching similarly pessimistic conclusions.

Eventually, research emerged examining how norms, or "standards of appropriate behavior for actors with a given identity" (Finnemore and Sikkink 1998, 891), exert a powerful influence over political processes, including solutions to collective action problems (March and Olsen 1984). Early work in this vein used agent-based models to demonstrate that strategies following a simple "norm of reciprocity" dictating cooperation with those who cooperated in the last interaction outperformed more selfish behavioral rules in repeated Prisoner's Dilemma games (Axelrod 1984, 1986).
Building on those theoretical results, Ostrom (1998, 2009) and her collaborators demonstrated the ability of groups to create and maintain norms of reciprocity to solve collective action problems in both the lab and the field. These real-world solutions avoided the non-cooperative outcomes predicted by game-theoretic models and widely cited applications of Olson's principles such as Hardin's (1968) Tragedy of the Commons model. Through a remarkable body of research, Ostrom demonstrated how adopting basic norms of reciprocity similar to those studied by Axelrod - though calibrated to the contours of a particular challenge and context — can help communities overcome collective action problems across a wide range of conditions. Scholarship in other areas of political science also demonstrated the importance of a variety of other norms for explaining a range of domestic political behavior, including corruption and clientelism (Helmke and Levitsky 2004), implementation of policies ranging from pollution controls (Winter and May 2001) to conscription (Levi 1997), and the adoption of new domestic policies (Raymond 2016; Crawford 2009; Mildenberger and Tingley 2019).

Meanwhile, there has been a robust but largely parallel literature in political science on the use of norms to shape the behavior of nations within the anarchic global system. Although this work draws on related concepts from norm theory, including norm cascades, internalization, and contestation (Finnemore and Sikkink 1998; Deitelhoff and Zimmermann 2020), it does so with a focus on states (or state leaders) as the key actors. In this respect, political science has often focused on norms as standards of appropriateness among governments, rather than among individual citizens. Yet for collective action problems such as ACC or COVID-19, we argue there is an urgent need to bring norm theory to bear on policies to promote individual behavior changes, even once a state has agreed to address the issue based on international pressure that may well include a normative element. In this respect, our paper addresses the issue of coordination "within countries" rather than "between countries," to use the helpful distinction introduced by Mildenberger and Tingley $(2019,1280)$.

Subsequent work outside political science has further clarified how social norms powerfully influence individual behavior, especially in situations where a person stands to benefit from free-riding. This work can improve our understanding of collective action solutions, especially for problems requiring the kinds of broad changes in individual behaviors relevant to challenges like ACC and COVID-19. A core insight of this interdisciplinary literature is that individuals are quite alert to other people's behaviors and assessments of behavior. Individual perceptions about what behaviors are common-even if such perceptions are inaccurate — can push individuals to bring their own conduct into closer conformity with what they perceive to be normal. Individuals may conform because of an expectation that the common behavior must be 
beneficial to the self (Muthukrishna, Morgan, and Henrich 2016). More interestingly, they may infer that what others are doing is what they themselves should also do, even in the absence of explicit rules (Davis, Hennes, and Raymond 2018; Roberts, Gelman, and Ho 2017; Tworek and Cimpian 2016). As a result, social norms can powerfully encourage collective action via actual or perceived social injunction, without requiring governance resources for incentives or penalties (Sripada and Stich 2005).

At the same time, the ACC and COVID-19 cases highlight under-examined boundary conditions to the utility of large-scale normative messaging strategies. That is, individuals are not equally alert or sensitive to everyone, but are extremely responsive to the group membership, status, and social identity of those other people from whom they obtain information and to whom they conform when calibrating their own assessments, decisions, and behaviors. This nuance, we argue, is a key barrier that has made governance challenges posed in hyper-politicized contexts so difficult to address, even with the use of social norms.

\section{Climate Change and COVID-19 as Severe Collective Action Problems}

ACC and COVID-19 share a cluster of key characteristics that make them especially "severe" collective action problems. At the same time, previous efforts to draw parallels between ACC and COVID-19 (e.g., Bouman, Steg, and Dietz 2020) have overlooked important areas of difference. Appreciating both the similarities and differences between these two cases can help to guide the selection and calibration of generalizable norm-based governance strategies.

\section{Core Similarities}

The similarities between the two cases are summarized in table 1. First, ACC and COVID-19 both fit the model of a collective action problem: they require behavior changes by individuals who face incentives to free ride. For example, the benefits gained by an individual who accepts a longer commute by using public transit to help fight
ACC are likely smaller than the (perceived) benefits they would gain by driving their own car to work. As a result, many people may choose to continue driving despite the adverse effects on the environment. Many challenges posed by COVID-19 share this structure: containing the disease requires changes in behavior-masking, physical distancing, vaccination, etc. - that may seem more costly to individuals than the incremental benefits those personal changes would have on stopping the spread of the virus. ${ }^{1}$ As with ACC, perceiving COVID-mitigating behaviors as costly creates an incentive to free ride by rejecting the recommended behaviors.

Moreover, both cases require substantial and widespread behavioral change. Successfully addressing ACC will require major alterations to basic energy use and consumer choices that permeate daily life. Similarly, addressing a pandemic like COVID-19 requires at least short-term changes to foundational social behaviors, from social interactions and movement to basic dress and appearance and even medical intervention. Motivating and enforcing these behavior changes across the vast majority of a diverse population is a tremendous governance challenge.

ACC and COVID-19 also share qualities that make them especially difficult collective action problems compared to the types of social dilemmas traditionally examined by social and political scientists. First, they are both politically hyper-polarized. Public opinion on ACC is deeply divided along partisan lines in the United States and elsewhere, with right-wing individuals and parties less likely to believe that climate change is anthropogenic or to support actions to mitigate it (Krange, Kaltenborn, and Hultman 2019; Carmichael, Brulle, and Huxster 2017; McCright, Dunlap, and Marquart-Pyatt 2016; Zhou 2016; McCright and Dunlap 2011; Gromet, Kunreuther, and Larrick 2013). Right-wing populist movements have also emerged as a potent oppositional force to action on ACC globally (Lockwood 2018; Forchtner 2019). Public opinion regarding the COVID-19 crisis breaks down along similar partisan lines, with conservative and rightwing populist individuals less supportive of masking, social distancing, and even COVID-19 vaccinations than

Table 1

Key similarities and differences between climate change and COVID-19

\begin{tabular}{ll}
\hline Similarities & Differences \\
\hline $\begin{array}{l}\text { 1. Collective action problem } \\
\text { 2. Requires widespread and substantial } \\
\text { behavior change }\end{array}$ & $\begin{array}{l}\text { 1. Greater potential to limit individual risk through unilateral actions in } \\
\text { COVID-19 case }\end{array}$ \\
$\begin{array}{ll}\text { 3. Greater importance of individual decision making (compared to } \\
\text { structural solutions) for COVID-19 }\end{array}$ \\
$\begin{array}{ll}\text { 3. Smaller short-term economic impacts from leading measures to mitigate } \\
\text { COVID-19 }\end{array}$ \\
mistrust of expertise & 4. Shorter term required behavior changes for COVID-19
\end{tabular}


members of other groups (Van Bavel et al. 2020; Allcott et al. 2020; Walsh 2020; Diamond 2021). This partisan split on COVID-19 also extends beyond the United States, with prominent right-wing leaders in other nations and their followers failing to support actions to limit the spread of the pandemic, often in nations that are facing some of the highest infection and mortality rates from the virus (Tharoor 2020; Drèze 2020).

Moreover, the complexity and politicization of both issues has contributed to pervasive misinformation and a widespread mistrust of expertise. Skepticism about climate science has long been fed by misinformation campaigns, where so-called "merchants of doubt" create confusion about basic ACC facts (Oreskes and Conway 2010; Benkler, Faris, and Roberts 2018; McCright and Dunlap 2000). The COVID-19 crisis has also been beset by scientific uncertainty, misinformation, and public mistrust of experts, and these too break down largely along partisan lines (Van Bavel et al. 2020). All of these qualities have hampered government attempts to promote effective collective action in response to the crisis.

These factors are especially important because, in obstructing mutual trust, they inhibit groups from arriving at a shared agreement on the character of the problem. Such shared agreement is critical to generating successful collective action (Ostrom 1998). Moreover, these factors generate especially acute challenges for problems like ACC and COVID-19, given emergent rhetoric that frames candidate solutions as conflicting with core partisan values (e.g., freedom and personal responsibility). In this regard, these types of collective action problems are likely to continue to arise in the future, as the scope of human impact on the planet generates more complex, global-scale problems that require widespread behavior changes, but that are also fertile ground for hyper-partisanship and [mis-]information transmission. ${ }^{2}$ Addressing these distinctive collective action problems will also likely require governance strategies that go beyond classic collective action solutions such as simple norms of reciprocity.

\section{Critical Differences}

Despite these important similarities between the COVID19 and ACC cases, there are also critical differences that are less frequently appreciated. The first is that individual actions a person can take to reduce the threat of ACC generally have a limited impact on their own exposure to that threat-indeed, this is part of what has made the problem seem intractable (Gardiner 2011). COVID-19, however, features a different quality of self/other symmetry with respect to mitigation actions. That is, individual actions taken to mitigate the collective risks of spreading COVID-19 like masking or distancing also substantially reduce one's personal risk of contracting the disease. This symmetry suggests additional norm-based strategies for the COVID-19 case with a greater focus on personal risks.

A second difference between the two challenges concerns how amenable each is to being addressed by largerscale "structural" changes compared to changes in individual decision-making. For example, climate activists and scholars have argued that structural solutions that change the decision-making context for all individuals, such as government energy taxes and subsidies or a new national energy infrastructure, will have dramatically more effect on ACC than individual behavioral choices related to energy conservation or recycling (e.g., Heglar 2019; Webb 2012). Substantially shifting the structural factors affecting many important COVID-19 protective decisions is more difficult, however, as shown by the difficulties of enforcing limits on private gatherings or mask mandates (Mystal 2020; Foss 2020). Improvements to infrastructure that make vaccines more available to different communities have had some impact on vaccination behavior (Irfan 2021). However, mitigating COVID-19 and similar pandemics will likely rely more on changing individual behavior and choices through social pressure and persuasion than on the kinds of large-scale structural changes that are likely to have the biggest impacts on ACC (Grunwald 2020).

A third key difference between the two cases stems from the expected economic impacts of government actions to mitigate COVID-19 and ACC. For ACC, the traditional (though contested) view is that many government responses will be fundamentally threatening to existing industries, jobs, and market systems (Hennes et al. 2016). COVID-19 presents a more complicated case. Although mitigation strategies such as stay-at-home orders are seen as deeply threatening to the global economy, others like masking and vaccines have been touted for their ability to protect the economic status quo-their use allows businesses to stay open and workers to remain employed (e.g., Hatzius, Stuyve, and Rosenberg 2020). In addition, behavior changes such as masking and social distancing required for COVID-19 mitigation are potentially shorter term compared to the behavior changes needed to address ACC, making them seem less costly.

Taken together, these differences suggest that government actions using norms to motivate behavior changes should, if anything, be especially promising for a problem like COVID-19: there are strong self-interest motivations for the required behaviors (e.g., personal health, return to normal activities), greater reliance on "self-policing" for desired behavior changes, and the behavior change can be framed as short term and therefore less costly.

\section{Norm-Based Governance Strategies for Severe Collective Action Problems}

Scholars within and beyond political science have argued that norms are central to policies that effectively tackle 
collective action problems (Nyborg et al. 2016; Abson et al. 2017; Farrow, Grolleau, and Ibanez 2017; Kline, Waring, and Salerno 2018; Goldberg, Gustafson, and van der Linden 2020). Much of the interdisciplinary literature on norm psychology and individual behavior change was inspired by observation of human's extraordinary capacities to cooperate, coordinate, and solve collective action problems relative to other species (Henrich 2017; Boyd 2017; Sripada and Stich 2005; Chudek and Henrich 2011; Morris et al. 2015; Bicchieri 2016; Kelly and Davis 2018; Kelly and Setman 2020). This literature also emphasizes the importance of individuals' group memberships and social identities for decisions about whom to trust, and with whom to cooperate and conform (Smaldino 2019). Thus, an integration of key theories from across the social and political sciences can help to inspire norm-based governance strategies that meet the challenges posed by hyper-politicization, misinformation, and mistrust.

In this section, we distill some of the most important implications from these literatures for improving governance related to severe collective action problems like COVID-19 and ACC. First, we explore ways of reframing policy solutions in terms of the norms and values likely to persuade different partisans. Second, we consider the distinctive roles of descriptive versus injunctive norms in the context of both individual and collective risks, highlighting the importance of messages about the typicality and normativity of a behavior within one's political group. Third, we consider the phenomenon of norm internalization, and analyze how it could inform the optimal deployment of external incentives to change behavior. Finally, we consider how challenges concerning misinformation and trust or distrust of different information sources can be understood in terms of epistemic norms, and suggest that these information-based aspects of collective action problems may themselves be amenable to norm-based interventions. Together, these four implications provide initial insights for governance strategies for addressing the type of severe collective action problems considered in this article. The four strategies we focus on are general, and far from exhaustiveindeed, more specific recommendations are included in our discussions of each one.

\section{Framing Normative Messages across Ideological Difference}

The world is often normatively ambiguous, full of decisions where it is not clear which norm is appropriate to follow. In addition, because individuals typically bear a number of different social identities, each associated with different norms, more than one identity-specific norm can seem applicable to a given situation. This raises an intriguing governance question: To what degree can people be nudged to reconceive of an issue in terms of an alternative norm-a norm they already accept but do not usually apply to the issue in question? Evidence suggests that different frames can lead people to apply one norm rather than another, thereby changing the way they evaluate and act with respect to the issue (e.g., Nelson, Clawson, and Oxley 1997). This relationship between an issue, the different norms that might realistically apply to it, and resulting attitudes and actions, has generated research on the opportunities and limitations of "normative reframing," a type of norm-based intervention that aims at building policy support for an issue by changing public perceptions of the norms that should regulate it (Raymond 2016; Raymond et al. 2014). ${ }^{3}$

Examples of this strategy can be found in work on "conflict displacing" frames. For example, portraying the death penalty in terms of an "innocence frame" highlighting the risk of mistakenly executing an innocent person can reduce support for capital punishment even among committed death penalty supporters (Baumgartner, De Boef, and Boydstun 2008). Rather than directly challenging the core values and norms of these supporters, promoters of the innocence frame foreground an alternative norm against killing innocent people for evaluating the issue. The alternative norm avoids direct conflict with, and so is less threatening to, other core values of death penalty supporters.

The strategy of normative reframing has been successfully applied to a number of ACC and sustainability issues. Environmental advocates used this strategy to overcome interest group opposition to a major ACC policy in the Northeastern United States in 2008 (the Regional Greenhouse Gas Initiative) by reframing the issue in terms of widely shared norms related to responsibility for harm from pollution and an equal public entitlement to the "atmospheric commons" (Raymond 2016). Frames casting ACC policies as economic development opportunities have also been used to generate wider public support by invoking norms of economic or public health equity for working class and disadvantaged communities (Rabe 2008; Méndez 2020). Similar conflict-displacing frames might dislodge right-wing opposition to COVID-mitigating behaviors such as masking, social distancing, or vaccinations. For example, messages could connect a COVID-mitigating behavior to protecting personal freedoms or protecting local communities - two norms associated with political conservativism. Alternatively, opponents of a wide range of ACC policies have undermined public support by framing the policies as violating norms of fairness, highlighting potentially increased energy costs for poor or working-class families (Lockwood 2018; Raymond 2020; Stokes 2020, 127) Thus, different levels of public support can be marshalled for a single policy idea depending on whether the policy is framed as violating or being in alignment with different shared norms. 
Work guided by moral foundations theory (Graham et al. 2013) has shown that political conservatives favor certain values, including loyalty, authority, sanctity, and liberty (Graham, Haidt, and Nosek 2009; Haidt 2012). Wolsko, Ariceaga, and Seiden (2016) found that frames stressing these conservative values increase pro-environmental attitudes and behavioral intentions in conservative individuals. Messages that connect environmental behavior to conservative values such as patriotism (Feygina, Jost, and Goldsmith 2010) and free enterprise (Hennes et al. 2016; Campbell and Kay 2014) have also proven effective. Similar work indicates that for political conservatives, "backward-looking" ACC frames focused on comparisons to their society's history are more effective than "forwardlooking" ones focused on gaining benefits or avoiding threats in the future (Baldwin and Lammers 2016). In addition, conservatives seem to be more open to frames that emphasize local impacts from ACC in particular (Wiest, Raymond, and Clawson 2015; Hart and Nisbet 2012). This work is closely related to research indicating that framing ACC in terms of local public health effects is effective for all partisan identities, including conservatives (Maibach et al. 2010; Raymond 2019).

Reframing strategies are well suited to address ACC, COVID-19, and other similarly large and complicated collective action problems, not only because they countenance normative ambiguity and the diversity of norms across social identities and political orientations, but also because they cast that ambiguity and diversity as providing opportunities. These norm-based interventions attempt to leverage the fact that people harbor a wide range of norms and embrace a variety of values, but also leave room for governments to differently calibrate the messaging around the norms and behaviors they are trying to encourage or discourage to better fit the sensibility of different sectors of the public.

\section{Using Descriptive and Injunctive Norm Messages to Mitigate Different Forms of Risk}

Early research on norm-based interventions often focused on perceptions of "descriptive norms"- behaviors that are common or normal. For example, research demonstrated that providing college students information about how uncommon binge drinking is among their peers can reduce this personally risky behavior (Lewis and Neighbors 2006). Thus, messages stressing the small number of people who refuse to wear masks or engage in other selfprotective behaviors such as vaccination, and highlighting how abnormal such deviance is, might be effective in persuading those who are not initially willing to engage in these actions. Messages based on descriptive norms have also proven to be effective at changing sustainability behaviors ranging from recycling to water conservation to home energy use (Cialdini, Reno, and Kallgren 1990;
Goldstein, Cialdini, and Griskevicius 2008; Allcott 2011). A related line of research finds a similar role for "secondorder beliefs"; for example, providing an individual with correct information about the prevalence of support for climate policy action among other citizens can increase the individual's personal support for such action (Mildenberger and Tingley 2019).

Intense partisanship can make it more important to emphasize the prevalence of a behavior or belief within the relevant political group. For example, emphasizing to conservatives the large or growing portion of the conservative population who concede that the global climate is changing, or who support new ACC policies, has been shown to increase both belief in ACC and behavioral intentions to address the problem (e.g., Bayes et al. 2020). Given the partisan nature of the COVID-19 case, describing the large number of co-partisans who are engaging in a desired behavior (or the small number who are refusing to) should be an especially important strategy for changing behaviors related to COVID-19 risk mitigation (see also Peters forthcoming). This approach could be supplemented by publicizing instances of prestigious leaders and individuals at the center of partisan networks modeling the prescribed behavior, and speaking out in favor of it (see Van Bavel et al. 2020).

Where a desirable behavior is still uncommon, research has shown that describing it as "trending" can be effective in getting people to adopt it (Mortensen et al. 2019). Information about these "dynamic" norms has been found to be effective in helping behaviors spread even before they are common (Sparkman and Walton 2017). Indeed, many political scientists and other scholars discuss these phenomena in terms of tipping points, where a new norm becomes widespread enough to trigger a "norm cascade" in which a critical mass of support leads to a rapid spread of the norm via imitation (Nyborg et al. 2016; Milkoreit et al. 2018; Otto et al. 2020).

Descriptive norm messages alone, however, may be insufficient to address collective challenges, especially in cases where personal risk is not significantly reduced by individual behavior change. Research has suggested that information about descriptive norms may be most effective when combined with descriptions of "injunctive" norms that express ideals of appropriate behavior, such as depictions of lowering one's thermostat being the "right" thing to do (Schultz et al. 2007; Mann and Hill 1984). More broadly, descriptive norm messages for collective action problems like ACC get a boost from being paired with injunctions prescribing social cooperation and reciprocity that emphasize a citizen's duty to do their part (Ostrom 1998; Miller and Prentice 2016; Sparkman, Howe, and Walton 2020). Highlighting these cooperative injunctive norms likely takes on greater importance for collective action problems like ACC where personal risk reductions from individual behavior changes are limited. 
Importantly, expressions of injunctive norms not only imply disapproval for failing to comply with the norm, but also convey social approval for engaging in the desired behavior. At a minimum, this can take the form of providing simple positive feedback to those who take actions such as getting vaccinated or wearing masks. In sum, this interdisciplinary literature suggests that public messages about descriptive norms alone are unlikely to be as effective as information about what is normal accompanied by a well-designed injunctive message.

\section{Leveraging Norm Internalization}

Many norm-based policies have emphasized the importance of "norm internalization," the process by which an individual comes to follow a norm for its own sake, without the need for external injunctions or incentives (Davis, Hennes, and Raymond 2018; Farrow, Grolleau, and Ibanez 2017; Kinzig et al. 2013). Once an individual has internalized a norm, following it becomes an end in itself (Kelly and Davis 2018). Moreover, individuals no longer have to think about the internalized norm explicitly, as they come to intuitively recognize and naturally respond to the circumstances in which it applies (Kelly and Setman 2020).

Most importantly from a governance perspective, individuals become motivated to comply with and enforce the internalized norm intrinsically, rather than just instrumentally (Gintis 2003; Henrich and Ensminger 2014; Gavrilets and Richerson 2017; Nichols 2021). Behaviors that are intrinsically rather than instrumentally motivated may be more likely to persist in the face of changes to circumstances or the removal of external incentives (Allcott and Rogers 2014; Fehr and Falk 2002). These qualities make norm internalization especially appealing for severe collective action problems. As more members of a group internalize a norm, the need for governmental actions to continue scaffolding the resulting norm-guided behavior is reduced. This psychological process may be especially important for trending norms, as those individuals who internalize a norm that is not yet widely accepted otherwise run the risk of engaging in behaviors that may seem costly, even if they are not confident that doing so will make a practical difference. Internalization may also be protective against the politicization of a behavior over time.

Norm internalization also provides a useful way to conceptualize dynamic interactions between individuals and the external structures to which they respond (Brownstein, Madva, and Kelly 2021; Waring, Goff, and Smaldino 2017). According to one account, once government interventions (such as improved mass transit or bike lanes) help create new patterns of behavior, people begin to infer and internalize the presence of injunctive norms that prescribe and regulate behaviors to help fight ACC (Kinzig et al. 2013). Similarly, governments should be able to promote norm internalization related to COVID-19 through policies that make the desired behaviors as easy as possible (e.g., the distribution of free masks or convenient vaccine locations). Interventions that can facilitate internalization have the potential to lower the need for longer-term governance strategies like communication campaigns or incentives aimed at changing behavior. The broad internalization of a new norm among the public can also start a positive feedback loop, establishing a new baseline of perceived "normal" behavior and making even more ambitious policy changes possible in the future (Levin et al. 2012).

"Norm avowal" is another emerging strategy for encouraging people to adopt new norms. An individual's avowed norms are those rules and principles that they have explicitly formulated, reflectively deliberated over, and consciously embraced (Kelly forthcoming). When a person explains and justifies the avowed norm to others in their community, they endorse it and signal a commitment to stand behind it (Calhoun 1995). The effects of such commitments are likely enhanced by publicly avowing them, creating reputational incentives to keep one's own behavior in line with the norms one has endorsed, and a motivational bulwark against social pressure to violate them (Michael, Sebanz, and Knoblich 2016; Cialdini 2021). This idea is supported by empirical work on environmental social dilemmas, where open reflection and deliberation about reasons for cooperating, as well as public declarations of an intention to cooperate, have a measurable effect on levels of cooperation (Ostrom 1998). Similar government programs could encourage people to "take the pledge" to follow behavioral norms such as walking to work or switching to renewable energy for ACC, or masking and social distancing in the case of COVID-19. ${ }^{4}$ Explicitly embracing a norm and incorporating it into one's personal identity, along with publicly endorsing it, may make it more likely to influence one's behavior across situations and social settings, and governments can take advantage of this by promoting norm avowal strategies.

At the same time, the imposition of new incentives onto a social setting that was previously structured by norms may "crowd out" intrinsic motivations for desired behaviors (Frederiks, Stenner, and Hobman 2015; see also Gneezy, Meier, and Rey-Biel 2011). Governments should be wary of using monetary incentives in particular, as these have been shown to sometimes undermine intrinsic normative motivation. This potential downside of financial incentives suggests that recent policy initiatives to pay reluctant individuals to get a COVID-19 vaccine (Loewenstein and Cryder 2020) should be closely monitored for their effectiveness, with special attention to the impact of such incentives on motivations to get additional booster vaccinations that may be required in the future. 


\section{Epistemic Norms}

Finally, work on "epistemic norms" is directly relevant to governance challenges related to misinformation found in the ACC and COVID-19 cases. Epistemic norms regulate how one ought to handle information and update beliefs and other epistemic states (Littlejohn and Turri 2014; Henderson 2020). For our purposes, the most important kinds of epistemic norms are guidelines about what sources of information are trustworthy. Some epistemic norms specify levels of trust for different individuals based on their social identity and group membership, such as the "believe women" injunction that was part of the campaign to raise awareness about issues of sexual assault and harassment. Others specify levels of trust for different institutions and their leaders, prescribing the appropriate level of deference for different experts. Relevant examples include norms that recommend skepticism about information issued by certain media sources and scientific experts that have become common in some right-wing groups. These norms of mistrust are reinforced by a long running campaign of misinformation about basic ACC facts that has increasingly focused on challenging the credibility of climate scientists and news sources (Cann and Raymond 2018; McCright and Dunlap 2000; Oreskes and Conway 2010; Benkler, Faris, and Roberts 2018).

This research illustrates an important point: it is not uncommon for epistemic norms to vary among different groups. Such variety can give rise to epistemic norms that create problematic phenomena like "echo chambers" and "epistemic bubbles" (Nguyen 2020; Edenberg and Michael 2021). Moreover, in polarized and partisan environments, publicly rejecting or avowing a norm identified with a specific group is one way for individuals to signal their identity and commitment to their own group and its values (Funkhouser 2020). Such performances, especially when they are costly in some way, can serve to solidify one's standing as a member of the group and to enhance one's reputation and credibility within it (Henrich 2009; Kahan et al. 2017; Schaffner and Luks 2018). Complying with epistemic norms that reject the authority of scientific experts or publicly avow false claims are performances that are well suited to perform this identity-signaling function, exactly because such irrational behaviors can be costly. Understanding this dynamic in terms of epistemic norms will make it easier to bring the resources of norm-based approaches to governance to bear on them. This, in turn will help governments more effectively influence the informational contexts in which complex collective action problems like ACC and COVID-19 will need to be addressed.

Consistent with these ideas is research suggesting that people are more influenced by climate science information presented to them by sources they trust (Bolin and
Hamilton 2018). Some argue that persuading partisans of the legitimacy of climate science is the key to changing attitudes and behavior (van der Linden, Leiserowitz, and Maibach 2019; Van Boven, Ehret, and Sherman 2018). Circumventing or otherwise surmounting the relevant epistemic norms of skepticism and distrust is likely to be key to achieving this objective.

Misinformation and partisan-based distrust of many information sources is also widespread in the case of COVID-19 (Allcott et al. 2020; Burszytn et al. 2020). This similarity suggests that public interventions designed to target epistemic norms should also be able to improve individual behavioral responses to the pandemic. Indeed, early research on communications related to COVID-19 has recommended using trusted local leaders to disseminate information about the disease, especially to get factual information out as early as possible to inoculate the public against subsequent misinformation and conspiracy theories (Van Bavel et al. 2020). Some of this work (e.g., Tworek, Beacock, and Ojo 2020) also indicates an additive effect of pairing reliable information from trusted sources with messages about personal autonomy and responsibility (values that are especially appealing to conservatives).

These findings imply a crucial lesson: Messengers matter. To be effective, advocates of norm-based governance strategies should incorporate messengers that are assigned high levels of trust by epistemic norms of partisan groups they are trying to reach. Related work indicates that these messengers may be particularly effective if they initially uncouple descriptive information about a problem from particular policy recommendations that may conflict with some recipient's values. This strategy may reduce denial of the existence of the problem motivated by reticence to engage in a particular value-inconsistent solution (e.g., Campbell and Kay 2014).

\section{Conclusion}

Governments continue to struggle with the complex nature of challenges presented by the COVID-19 crisis, much as they have struggled with similar issues for responding to ACC. In this paper, we note similarities between the COVID-19 and ACC cases that make them prime examples of a new type of severe collective action problem: the highly disruptive behavior changes required, their hyper-partisan nature, and the prevalence of scientific misinformation that helps create an atmosphere of distrust in experts and other elites. Inspired by these similarities, we connect recent interdisciplinary work on norm psychology to early political science work on basic norms of reciprocity in Prisoner's Dilemma games to refine familiar ideas and formulate new ones to help address such challenges. We offer a range of norm-based governance 
strategies for improving collective action on both problems and others like them, including:

1. Framing normative messages across ideological difference, including appeals to values central to those resisting behavior change (such as personal freedom, patriotism, or local communities);

2. Integrating descriptive and injunctive norm messages;

3. Promoting norm internalization and avowal, especially in conjunction with external incentives; and

4. Leveraging epistemic norms regarding trusted sources of information in disseminating information on these severe collective action problems.

In a world where extreme and polarized political identities are gaining strength and where new information technologies are making misinformation a far greater threat, severe collective action problems similar to ACC or COVID-19 are likely to become more common in the future. Thus, it is critical for political scientists to consider and develop strategies for helping society to solve collective action challenges exacerbated by these trends. Stronger engagement with insights from across the behavioral sciences can help political scientists and policy analysts generate the governance strategies needed to meet this challenge. Our recommendations offer a starting point for paving a path for successful norm-based governance in an era of hyper-politicization.

\section{Notes}

1 This may be especially true in the case of young people who appear to face lower risks of serious health complications from COVID-19 and who remained a key group as of 2021 failing to get a COVID-19 vaccination; Adams et al. 2021.

2 Some leading candidates for future severe collective action problems include antibiotic resistance, water pollution and aquifer depletion from agriculture, and other aspects of core behaviors like drug use and food production featuring uncertain information and the need for potentially coercive rules.

3 For an important variation on this normative reframing approach, we note also the emerging strategy of attempting to create entirely new norms for such issues, such as a potential new norm against fossil fuel use promoted by some climate activists; Green 2018.

4 Indeed, some leading organizations have adopted a pledge-based strategy to increase compliance with COVID-19 mitigation behaviors, such as Purdue University (https://protect.purdue.edu/pledge/).

\section{References}

Abson, David J., Joern Fischer, Julia Leventon, Jens Newig, Thomas Schomerus, Ulli Vilsmaier, Henrik
Von Wehrden, Paivi Abernethy, Christopher D. Ives, Nicolas W. Jager, and Daniel J. Lang. 2017. "Leverage Points for Sustainability Transformation." Ambio 46(1): 30-39.

Adams, Sally H., Jason P. Schaub, Jason M. Nagata, M. Jane Park, Claire D. Brindis, and Charles E. Irwin, Jr. 2021. "Young Adult Perspectives on COVID-19

Vaccinations." Journal of Adolescent Health 69(3): 511-14.

Allcott, Hunt. 2011. "Social Norms and Energy

Conservation." Journal of Public Economics 95(9-10): 1082-95.

Allcott, Hunt, Levi Boxell, Jacob Conway, Matthew Gentzkow, Michael Thaler, and David Yang. 2020.

"Polarization and Public Health: Partisan Differences in Social Distancing During the Coronavirus Pandemic." Journal of Public Economics 191. https:// doi.org/10.1016/j.jpubeco.2020.104254

Allcott, Hunt, and Todd Rogers. 2014. "The Short-Run and Long-Run Effects of Behavioral Interventions: Experimental Evidence from Energy Conservation." American Economic Review 104(10): 3003-37.

Axelrod, Robert. 1984. The Evolution of Cooperation. New York: Basic Books.

_. 1986. "An Evolutionary Approach to Norms." American Political Science Review 80(4): 1095-111.

Baldwin, Matthew, and Joris Lammers. 2016. "Past-Focused Environmental Comparisons Promote Proenvironmental Outcomes for Conservatives." Proceedings of the National Academy of Sciences 113(52): 14953-57.

Baumgartner, Frank R., Suzanna L. De Boef, and Amber E. Boydstun. 2008. The Decline of the Death Penalty and the Discovery of Innocence. New York: Cambridge University Press.

Bayes, Robin, James N. Druckman, Avery Goods, and Daniel C. Molden. 2020. "When and How Different Motives Can Drive Motivated Political Reasoning." Political Psychology 41(5): 1031-52.

Benkler, Yochai, Robert Faris, and Hal Roberts. 2018. Network Propaganda: Manipulation, Disinformation, and Radicalization in American Politics. New York: Oxford University Press.

Bicchieri, Cristina. 2016. Norms in the Wild: How to Diagnose, Measure, and Change Social Norms.

New York: Oxford University Press.

Bolin, Jessica L., and Lawrence C. Hamilton. 2018. "The News You Choose: News Media Preferences Amplify Views on Climate Change." Environmental Politics 27(3): 455-76.

Bouman, Thijs, Linda Steg, and Thomas Dietz. 2020. "Insights From Early COVID-19 Responses About Promoting Sustainable Action." Nature Sustainability 4: 194-200.

Boyd, Robert. 2017. Different Kind of Animal: How Culture Transformed Our Species. Princeton, NJ.: Princeton University Press. 
Brownstein, Michael, Alex Madva, and Daniel Kelly. 2021. "Individualism, Structuralism, and Climate Change." Environmental Comunication. https:// doi.org/10.1080/17524032.2021.1982745

Burszytn, Leonardo, Aakaash Rao, Christopher Roth, and David Yanagizawa-Drott. 2020. "Misinformation during a Pandemic." University of Chicago, Becker Friedman Institute for Economics Working Paper No. 2020-44. (https://papers.ssrn.com/sol3/ papers.cfm?abstract_id=3580487).

Calhoun, Cheshire. 1995. "Standing for Something." Journal of Philosophy 92(5): 235-60.

Campbell, Troy H., and Aaron C. Kay. 2014. "Solution Aversion: On the Relation Between Ideology and Motivated Disbelief." Journal of Personality and Social Psychology 107(5): 809-24.

Cann, Heather W., and Leigh Raymond. 2018. "Does Climate Denialism Still Matter? The Prevalence of Alternative Frames in Opposition to Climate Policy." Environmental Politics 27(3): 433-54.

Carmichael, Jason T., Robert J. Brulle, and Joanna K. Huxster. 2017. "The Great Divide: Understanding the Role of Media and Other Drivers of the Partisan Divide in Public Concern over Climate Change in the USA, 2001-2014." Climatic Change 141:599-612.

Chudek, Maciej, and Joeseph Henrich. 2011. "CultureGene Coevolution, Norm-Psychology and the Emergence of Human Prosociality." Trends in Cognitive Sciences 15(5): 218-26.

Cialdini, Robert B. 2021. Influence, New and Expanded: The Psychology of Persuasion. New York: Harper Business.

Cialdini, Robert B., Raymond R. Reno, and Carl A. Kallgren. 1990. "A Focus Theory of Normative Conduct: Recycling the Concept of Norms to Reduce Littering in Public Places." Journal of Personality and Social Psychology 58(6): 1015-26.

Crawford, Neta C. 2009. "Homo Politicus and Argument (Nearly) All the Way Down: Persuasion in Politics." Perspectives on Politics 7(1): 103-24.

Davis, Taylor, Erin P. Hennes, and Leigh Raymond. 2018. "Normative Motivation and Sustainable Behavior: New Insights from an Evolutionary Perspective." Nature Sustainability 1(5): 218-24.

Deitelhoff, Nicole, and Lisbeth Zimmermann. 2020. "Things We Lost in the Fire: How Different Types of Contestation Affect the Robustness of International Norms." International Studies Review 22(1): 51-76.

Diamond, Dan. 2021. "We Want to be Educated, Not Indoctrinated,' Say Trump Voters Wary of Coronavirus Vaccination." Washington Post, March 15. (https:// www.washingtonpost.com/health/2021/03/15/ vaccine-hesitant-republicans-focus-group/).

Drèze, Jean. 2020. "India Is in Denial about the COVID19 Crisis.” Scientific American, August 25. (https:// www.scientificamerican.com/article/india-is-in-denialabout-the-covid-19-crisis/).

Edenberg, Elizabeth, and Hannon Michael. 2021. Political Epistemology. Oxford: Oxford University Press.

Farrow, Katherine, Gilles Grolleau, and Lisette Ibanez. 2017. "Social Norms and Pro-environmental Behavior: A Review of the Evidence." Ecological Economics 140: 1-13. https://doi.org/10.1016/j.ecolecon.2017.04.017

Fehr, Ernst, and Armin Falk. 2002. "Psychological Foundations of Incentives." European Economic Review 46(4): 687-724.

Feygina, Irina, John T. Jost, and Rachel E. Goldsmith. 2010. "System Justification, the Denial of Global Warming, and the Possibility of 'System-Sanctioned Change.". Personality and Social Psychology Bulletin 36(3): 326338.

Finnemore, Martha, and Kathryn Sikkink. 1998. "International Norm Dynamics and Political Change." International Organization 52(4): 887-917.

Forchtner, Bernhard. 2019. "Climate Change and the Far Right." Wiley Interdisciplinary Reviews: Climate Change 10(5): 1-11.

Foss, Sara. 2020. "How to Enforce Social Distancing?" Daily Gazette, June 15. (https://

dailygazette.com/2020/06/15/foss-how-to-enforcesocial-distancing/).

Frederiks, Elisha R., Karen Stenner, and Elizabeth V. Hobman. 2015. "Household Energy Use: Applying Behavioural Economics to Understand Consumer Decision-Making and Behaviour." Renewable and Sustainable Energy Reviews 41:1385-94.

Funkhouser, Eric. 2020. "A Tribal Mind: Beliefs that Signal Group Identity or Commitment." Mind \& Language. https://doi.org/10.1111/mila.12326

Gardiner, Stephen M. 2011. The Perfect Moral Storm: The Ethical Tragedy of Climate Change. New York: Oxford University Press.

Gavrilets, Sergey, and Peter J. Richerson. 2017. "Collective Action and the Evolution of Social Norm Internalization." Proceedings of the National Academy of Sciences 114(23): 6068-73.

Gintis, Herbert. 2003. “The Hitchhiker's Guide to Altruism: Gene-Culture Coevolution, and the Internalization of Norms." Journal of Theoretical Biology 220(4): 407-18.

Gneezy, Uri, Stephan Meier, and Pedro Rey-Biel. 2011. "When and Why Incentives (Don't) Work to Modify Behavior." Journal of Economic Perspectives 25(4): 191-210.

Goldberg, Matthew H., Abel Gustafson, and Sander van der Linden. 2020. "Leveraging Social Science to Generate Lasting Engagement with Climate Change Solutions." One Earth 3(3): 314-24.

Goldstein, Noah J., Robert B. Cialdini, and Vladas Griskevicius. 2008. "A Room with a Viewpoint: Using 
Social Norms to Motivate Environmental Conservation in Hotels." Journal of Consumer Research 35(3): 472-82.

Graham, Jesse, Jonathan Haidt, Sena Koleva, Matt Motyl, Ravi Iyer, Sean P. Wojcik, and Peter H. Ditto. 2013. "Chapter Two-Moral Foundations Theory: The Pragmatic Validity of Moral Pluralism." Advances in Experimental Social Psychology 47:55-130. https:// doi.org/10.1016/B978-0-12-407236-7.00002-4

Graham, Jesse, Jonathan Haidt, and Brian A. Nosek. 2009. "Liberals and Conservatives Rely on Different Sets of Moral Foundations." Journal of Personality and Social Psychology 96(5): 1029-46.

Green, Fergus. 2018. “Anti-Fossil Fuel Norms." Climatic Change 150(1-2): 103-16.

Gromet, Dena M., Howard Kunreuther, and Richard P. Larrick. 2013. "Political Ideology Affects EnergyEfficiency Attitudes and Choices." Proceedings of the National Academy of Sciences 110(23): 9314-19.

Grunwald, Michael. 2020. "What Covid Is Exposing about the Climate Movement." Politico, April 21. (https://www.politico.com/news/magazine/2020/04/ 21/earth-day-individual-climate-impact-198835).

Haidt, Jonathan. 2012. The Righteous Mind: Why Good People Are Divided by Politics and Religion. New York: Pantheon Books.

Hardin, Garrett. 1968. "The Tragedy of the Commons." Science 162(3859): 1243-48.

Hart, P. Sol, and Erik C. Nisbet. 2012. "Boomerang Effects in Science Communication: How Motivated Reasoning and Identity Cues Amplify Opinion Polarization about Climate Mitigation Policies." Communication Research 39(6): 701-23.

Hatzius, Jan, Daan Stuyve, and Isabella Rosenberg. 2020. "Face Masks and GDP." Goldman Sachs Global Economics Analyst, June 29.

Heglar, Mary A. 2019. "I Work in the Environmental Movement. I Don't Care If You Recycle.” Vox.com, June 4. (https://www.vox.com/the-highlight/2019/5/ 28/18629833/climate-change-2019-green-new-deal).

Helmke, Gretchen, and Steven Levitsky. 2004. "Informal Institutions and Comparative Politics: A Research Agenda." Perspectives on Politics 2(4): 725-40.

Henderson, David. 2020. "Are Epistemic Norms Fundamentally Social Norms?” Episteme 17(3): 281-300.

Hennes, Erin P., Benjamin C. Ruisch, Irina Feygina, Christopher A. Monteiro, and John T. Jost. 2016. "Motivated Recall in the Service of the Economic System: The Case of Anthropogenic Climate Change." Journal Experimental Psychology: General 145(6): 755-71.

Henrich, Joseph. 2009. "The Evolution of Costly Displays, Cooperation and Religion." Evolution and Human Behavior 30(4): 244-60.
. 2017. The Secret of Our Success: How Culture Is Driving Human Evolution, Domesticating Our Species, and Making Us Smarter. Princeton, NJ: Princeton University Press.

Henrich, Joseph, and Jean Ensminger. 2014. "Theoretical Foundations: The Coevolution of Social Norms, Intrinsic Motivation, Markets, and the Institutions of Complex Societies." In Experimenting with Social Norms: Fairness and Punishment in Cross-cultural Perspective, ed. Jean Ensminger and Joseph Henrich, 19-44. New York: Russell Sage Foundation.

Irfan, Umair. 2021. "The 4 Main Fault Lines That Divide the Vaccinated and the Unvaccinated." Vox. com, July 29. (https://www.vox.com/22587443/ covid-19-vaccine-refusal-hesitancy-variant-deltacases-rate).

Kahan, Dan M., Asheley Landrum, Katie Carpenter, Laura Helft, and Kathleen Hall Jamieson. 2017. "Science Curiosity and Political Information Processing." Political Psychology 38(S1): 179-99.

Kelly, Daniel. Forthcoming. "Two Ways to Adopt a Norm: On the (Moral?) Psychology of Internalization and Avowal." In The Oxford Handbook of Moral Psychology, ed. Manuel Vargas and John M Doris. New York: Oxford University Press.

Kelly, Daniel, and Taylor Davis. 2018. "Social Norms and Human Normative Psychology." Social Philosophy and Policy 35(1): 54-76.

Kelly, Daniel, and Stephen Setman. 2020. "The Psychology of Normative Cognition.” In The Stanford Encyclopedia of Philosophy. (https://plato.stanford.edu/ archives/fall2020/entries/psychology-normativecognition/).

Kinzig, Ann P., Paul R. Ehrlich, Lee J. Alston, Kenneth Arrow, Scott Barrett, Timothy G. Buchman, Gretchen C. Daily, Bruce Levin, Simon Levin, Michael Oppenheimer, Elinor Ostrom, and Donald Saari. 2013. "Social Norms and Global Environmental Challenges: The Complex Interaction of Behaviors, Values, and Policy." Bioscience 63(3): 164-75.

Kline, Michelle A., Timothy M. Waring, and Jonathan Salerno. 2018. "Designing Cultural Multilevel Selection Research For Sustainability Science." Sustainable Science 13(1): 9-19.

Krange, Olve, Bjørn P. Kaltenborn, and Martin Hultman. 2019. "Cool Dudes in Norway: Climate Change Denial among Conservative Norwegian Men.” Environmental Sociology 5(1): 1-11.

Levi, Margaret. 1997. Consent, Dissent, and Patriotism. Cambridge: Cambridge University Press.

Levin, Kelly, Benjamin Cashore, Steven Bernstein, and Graeme Auld. 2012. "Overcoming the Tragedy of Super Wicked Problems: Constraining Our Future Selves to Ameliorate Global Climate Change." Policy Sciences 45(2): 123152. 
Lewis, Melissa A., and Clayton Neighbors. 2006. "Social Norms Approaches Using Descriptive Drinking Norms Education: A Review of the Research on Personalized Normative Feedback." Journal of American College Health 54(4): 213-18.

Littlejohn, Clayton, and John Turri. 2014. Epistemic Norms: New Essays on Action, Belief, and Assertion. Oxford: Oxford University Press.

Lockwood, Matthew. 2018. "Right-Wing Populism and the Climate Change Agenda: Exploring the Linkages." Environmental Politics 27(4): 712-32.

Loewenstein, George, and Cynthia Cryder. 2020. "Why Paying People To Be Vaccinated Could Backfire." New York Times, December 15. (https:// www.nytimes.com/2020/12/14/upshot/covid-vaccinepayment.html).

Maibach, Edward W., Matthew Nisbet, Paula Baldwin, Karen Akerlof, and Guoqing Diao. 2010. "Reframing Climate Change as a Public Health Issue: An Exploratory Study of Public Reactions." BMC Public Health 10(1): 299. https://doi.org/10.1186/14712458-10-299

Mann, Millard F., and Thomas Hill. 1984. "Persuasive Communications and the Boomerang Effect: Some Limiting Conditions to the Effectiveness of Positive Influence Attempts." Advances in Consumer Research 11:66-70.

March, James G., and Johan P. Olsen. 1984. "The New Institutionalism: Organizational Factors in Political Life." American Political Science Review 78(4): 734-49.

McCright, Aaron M., and Riley E. Dunlap. 2000. "Challenging Global Warming as a Social Problem: An Analysis of the Conservative Movement's Counterclaims." Social Problems 47(4): 499-522.

- 2011. "The Politicization of Climate Change and Polarization in the American Public's Views of Global Warming 2001-2010." Sociological Quarterly 52: 155-94.

McCright, Aaron M., Riley E. Dunlap, and Sandra T. Marquart-Pyatt. 2016. "Political Ideology and Views about Climate Change in the European Union." Environmental Politics 25(2): 338-38.

Méndez, Michael. 2020. Climate Change from the Streets: How Conflict and Collaboration Strengthen the Environmental Justice Movement. New Haven, CT: Yale University Press.

Michael, John, Natalie Sebanz, and Günther Knoblich. 2016. "The Sense of Commitment: A Minimal Approach." Frontiers in Psychology. https:// doi.org/10.3389/fpsyg.2015.01968

Mildenberger, Matto, and Dustin Tingley. 2019. "Beliefs about Climate Beliefs: The Importance of SecondOrder Opinions for Climate Politics." British Journal of Political Science 49(4): 1279-307.
Milkoreit, Manjana, Jennifer Hodbod, Jacopo Baggio, Karina Benessaiah, Rafael Calderón-Contreras, Jonathan F. Donges, Jean-Denis Mathias, Juan Carlos Rocha, Michael Schoon, and Saskia E. Werners. 2018. "Defining Tipping Points for Social-Ecological Systems Scholarship: An Interdisciplinary Literature Review." Environmental Research Letters 13(3): 33005.

Miller, Dale T., and Deborah A. Prentice. 2016. "Changing Norms to Change Behavior." Annual Review of Psychology 67(1): 339-61.

Morris, Michael W., Ying-yi Hong, Chi-yue Chiu, and Zhi Liu. 2015. "Normology: Integrating Insights about Social Norms to Understand Cultural Dynamics." Organizational Behavior and Human Decision Processes 129:1-13.

Mortensen, Chad R., Rebecca Neel, Robert B. Cialdini, Christine M. Jaeger, Ryan P. Jacobson, and Megan M. Ringel. 2019. "Trending Norms: A Lever for Encouraging Behaviors Performed by the Minority." Social Psychological and Personality Science 10(2): 201-10.

Muthukrishna, Michael, Thomas J. H. Morgan, and Joseph Henrich. 2016. "The When and Who of Social Learning and Conformist Transmission." Evolution and Human Behavior 37(1): 10-20.

Mystal, Elie. 2020. "Covid Is about to Become the Newest Excuse for Police Brutality." The Nation, May 5. (https://www.thenation.com/article/society/ coronavirus-police-brutality/).

Nelson, Thomas E., Rosalee A. Clawson, and Zoe M. Oxley. 1997. "Media Framing of a Civil Liberties Conflict and Its Effect on Tolerance." American Political Science Review 91(3): 567-83.

Nguyen, C. Thi. 2020. "Echo Chambers and Epistemic Bubbles.” Episteme 17(2): 141-61.

Nichols, Shaun. 2021. Rational Rules: Towards a Theory of Moral Learing. Oxford: Oxford University Press.

Nyborg, Karine, John M. Anderies, Astrid Dannenberg, Therese Lindahl, Caroline Schill, Maja Schluter, W. Neil Adger, Kenneth J. Arrow, Scott Barrett, Steven Carpenter, F. Stuart Chapin III, Anne-Sophie Crépin, Gretchen Daily, Paul Ehrlich, Carl Folke, Wander Jager, Nils Kautsky, Simon A. Levin, Ole Jacob Madsen, Stephen Polasky, Marten Scheffer, Brian Walker, Elke U. Weber, James Wilen, Anastasios Xepapadeas, and Aart de Zeeuw. 2016. "Social Norms as Solutions." Science 354(6308): 42-43.

Olson, Mancur. 1965. The Logic of Collective Action. Cambridge, MA: Harvard University Press.

Oreskes, Naomi, and Erik M. Conway. 2010. Merchants of Doubt: How a Handful of Scientists Obscured the Truth on Issues from Tobacco Smoke to Global Warming. London, UK: Bloomsbury Press.

Ostrom, Elinor. 1998. "A Behavioral Approach to the Rational Choice Theory of Collective Action: 
Presidential Address, American Political Science Association." American Political Science Review 92(1): $1-22$.

—. 2009. "A General Framework for Analyzing Sustainability of Social-Ecological Systems." Science 325(5939): 419-22.

Otto, Ilona M., Jonathan F. Donges, Roger Cremades, Avit Bhowmik, Richard J. Hewitt, Wolfgang Lucht, Johan Rockström, Franziska Allerberger, Mark McCaffrey, Sylvanus S.P. Doe, Alex Lenferna, Nerea Morán, Detlef P. van Vuuren, and Hans Joachim Schellnhuber. 2020. "Social Tipping Dynamics for Stabilizing Earth's Climate by 2050." Proceedings of the National Academy of Sciences 117(5): 2354-65.

Peters, Uwe. Forthcoming. "Science Communication and the Problematic Impact of Desriptive Norms." British Journal for the Philosophy of Science.

Rabe, Barry G. 2008. "States on Steroids: The Intergovernmental Odyssey of American Climate Policy." Review of Policy Research 25(2): 105-28.

Raymond, Leigh. 2016. Reclaiming the Atmospheric Commons. Cambridge, MA: MIT Press.

_ 2019. "Policy Perspective: Building Political Support for Carbon Pricing-Lessons From Cap-andTrade Policies." Energy Policy. https://doi.org/10.1016/ j.enpol.2019.110986

- 2020. "Carbon Pricing and Economic Populism:

The Case of Ontario." Climate Policy 20(9): 1127-40.

Raymond, Leigh, Laurel S. Weldon, Daniel Kelly, Ximena Arriaga, B., and Ann Marie Clark. 2014. "Making Change: Norm-Based Strategies for Institutional Change to Address Intractable Problems." Political Research Quarterly 67(1): 197-211.

Roberts, Steven O., Susan A. Gelman, and Arnold K. Ho. 2017. "So It Is, So It Shall Be: Group Regularities License Children's Prescriptive Judgments." Cognitive Science 41(Suppl 3): 576-600.

Schaffner, Brian F., and Samantha Luks. 2018.

"Misinformation or Expressive Responding? What an Inauguration Crowd Can Tell Us about the Source of Political Misinformation in Surveys." Public Opinion Quarterly 82(1): 135-47.

Schultz, P. Wesley, Jessica Nolan, M., Robert Cialdini, B., Noah Goldstein, J., and Vladas Griskevicius. 2007. "The Constructive, Destructive, and Reconstructive Power of Social Norms." Psychological Science 18(5): 429-34.

Smaldino, Paul E. 2019. "Social Identity and Cooperation in Cultural Evolution.” Behavioural Processes 161:108-16.

Sparkman, Gregg, Lauren Howe, and Greg Walton. 2020. "How Social Norms Are Often a Barrier to Addressing Climate Change but Can Be Part of the Solution."

Behavioural Public Policy 5(4): 528-55.

Sparkman, Gregg, and Gregory M Walton. 2017.

"Dynamic Norms Promote Sustainable Behavior, Even if it is Counternormative." Psychological Science 28(11): 1663-74.

Sripada, Chandra S., and Steven Stich. 2005. "A Framework for the Psychology of Norms." In Innateness and the Structure of the Mind, ed. Peter Carruthers, Stephen Laurence, and Stephen Stich, 280-301. Oxford: Oxford University Press.

Stokes, Leah C. 2020. Short Circuiting Policy: Interest Groups and the Battle over Clean Energy and Climate Policy in the American States. New York: Oxford University Press.

Tharoor, Ishaan. 2020. "Bolsonaro May Be the World's Coronavirus Skeptic in Chief." Washington Post, April 7. (https://www.washingtonpost.com/world/2020/04/ 07/bolsonaro-may-be-worlds-coronavirus-skepticin-chief/).

Tworek, Christina M., and Andrei Cimpian. 2016. "Why Do People Tend to Infer 'Ought' from 'Is'? The Role Biases in Explanation.” Psychological Science 27(8): 1109-22.

Tworek, Heidi, Ian Beacock, and Eseohe Ojo. 2020. Democratic Health Communications During Covid-19: A RAPID Response. Vancouver: UBC Centre for the Study of Democratic Institutions.

Van Bavel, Jay J., Katherine Baicker, Paulo S. Boggio, Valerio Capraro, Aleksandra Cichocka, Mina Cikara, Molly J. Crockett, Alia J. Crum, Karen M. Douglas, James N. Druckman, John Drury, Oeindrila Dube, Naomi Ellemers, Eli J. Finkel, James H. Fowler, Michele Gelfand, Shihui Han, S. Alexander Haslam, Jolanda Jetten, Shinobu Kitayama, Dean Mobbs, Lucy E. Napper, Dominic J. Packer, Gordon Pennycook, Ellen Peters, Richard E. Petty, David G. Rand, Stephen D. Reicher, Simone Schnall, Azim Shariff, Linda J. Skitka, Sandra Susan Smith, Cass R. Sunstein, Nassim Tabri, Joshua A. Tucker, Sander van der Linden, Paul van Lange, Kim A. Weeden, Michael J. A. Wohl, Jamil Zaki, Sean R. Zion, and Robb Willer. 2020. "Using Social and Behavioural Science to Support COVID-19 Pandemic Response.” Nature Human Behavior 4(5): 460-71.

Van Boven, Leaf, Phillip J. Ehret, and David K. Sherman. 2018. "Psychological Barriers to Bipartisan Public Support for Climate Policy." Perspectives on Psychological Science 13(4): 492-507.

van der Linden, Sander, Anthony Leiserowitz, and Edward Maibach. 2019. "The Gateway Belief Model: A Large-Scale Replication.” Journal of Environmental Psychology 62:49-58.

Walsh, Bryan. 2020. "The U.S. Divide on Coronavirus Masks.” Axios, June 24. (https://www.axios.com/ political-divide-coronavirus-masks-1053d5bd-deb34cf4-9570-0ba492134f3e.html).

Waring, Timothy M., Sandra H. Goff, and Paul E. Smaldino. 2017. "The Coevolution of Economic 
Institutions and Sustainable Consumption Via Cultural Group Selection.” Ecological Economics 131:524-32.

Webb, Janette. 2012. "Climate Change and Society: The Chimera of Behaviour Change Technologies." Sociology 46(1): 109-25.

Wiest, Sara L., Leigh Raymond, and Rosalee A. Clawson. 2015. "Framing, Partisan Predispositions, and Public Opinion on Climate Change." Global Environmental Change 31:187-98.

Winter, Søren C., and Peter J. May. 2001. "Motivation for Compliance with Environmental Regulations."
Journal of Policy Analysis and Management 20(4): 675-98.

Wolsko, Christopher, Hector Ariceaga, and Jesse Seiden. 2016. "Red, White, and Blue Enough To Be Green: Effects of Moral Framing on Climate Change Attitudes and Conservation Behaviors." Journal of Experimental Social Psychology 65:7-19.

Zhou, Jack. 2016. "Boomerangs versus Javelins: How Polarization Constrains Communication on Climate Change." Environmental Politics 25(5): 788-811. 